\title{
Association Between Obstructive Sleep Apnea and Osteoporosis: A Systematic Review and Meta-Analysis
}

\author{
Sikarin Upala, ${ }^{1,2}$ Anawin Sanguankeo, ${ }^{1,2, *}$ and Soontharee Congrete ${ }^{3}$ \\ ${ }^{1}$ Department of Internal Medicine, College of Physicians and Surgeons, Bassett Medical Center and Columbia University, New York, USA \\ ${ }^{2}$ Department of Preventive and Social Medicine, Faculty of Medicine Siriraj Hospital, Mahidol University, Bangkok, Thailand \\ ${ }^{3}$ Department of Medicine, St. Elizabeth's Medical Center, Boston, Massachusetts, USA \\ "Corresponding author: Anawin Sanguankeo, Department of Internal Medicine, Bassett Medical Center, 1 Atwell Road, Cooperstown, New York, USA. Tel: +1-6075474805, Fax: \\ +1-6075476612, E-mail: anawin.sanguankeo@bassett.org
}

Received 2016 January 13; Revised 2016 June 10; Accepted 2016 June 20.

\begin{abstract}
Context: Hypoxia reduces osteoblast growth resulting in bone thinning and osteoporosis. Although obstructive sleep apnea (OSA) with recurrent hypoxia might be a contributing factor for osteoporosis development, whether OSA is a risk or protective factor for osteoporosis has not been demonstrated.

Objectives: This systematic review and meta-analysis evaluated the association between OSA and osteoporosis using published observational studies.

Data Sources: PubMed/MEDLINE and EMBASE databases

Study Selection: We completed a systematic review and meta-analysis of published observational studies that evaluated incidence or prevalence of osteoporosis or bone mineral density in obstructive sleep apnea compared with controls. Severity of OSA was characterized using the apnea-hypopnea index (AHI).

Data Extraction: Primary outcomes were incidence, prevalence, or odds ratio of having osteoporosis, defined as bone mineral density T-score $<-2.5 \mathrm{SD}$.

Results: Of 353 articles, 344 articles were excluded, 9 underwent full-length review and data were extracted from 7 studies consisting of 113,558 patients. Finally, 3 extracted studies were included in the meta-analysis of osteoporosis. Among cohort studies, the pooled odds ratio of osteoporosis in patients with OSA was 1.92 (95\% confidence interval [CI]: 1.24 - 2.97) compared with controls. Among cross-sectional studies, odds of osteoporosis was higher in controls compared with patients with OSA (OR $=0.60,95 \% \mathrm{CI}$ : 0.42 - 0.87 ). In subgroup analysis by gender and study design, in both sexes, only cohort studies had higher odds of osteoporosis compared with controls.

Conclusions: There was significant association between OSA and osteoporosis in studies with cohort design. Further prospective studies with large numbers of patients adjusted for the effects of age, sex, or BMI are required to comprehensively determine whether OSA is a risk factor for osteoporosis.
\end{abstract}

Keywords: Obstructive Sleep Apnea, Osteoporosis, Risk, Systematic Review, Meta-Analysis

\section{Context}

Obstructive sleep apnea (OSA) affects about $4 \%$ of men and $2 \%$ of women in the adult population (1). It is a common sleep disorder characterized by repetitive upper airway collapse with apnea/hypopnea and recurrent hypoxia during sleep, which results in fragmented sleep and intermittent drops in arterial blood oxygen saturation (hypoxemia) (2). The potential consequences of OSA involve multiple systems including cardiovascular, endocrine, and respiratory and neurocognitive dysfunction. For example, OSA causes multiple deleterious cardiovascular effects including hypertension, ischemic heart disease, stroke, pulmonary hypertension, cardiac arrhythmia, and cardiovas- cular mortality (3). Thus, OSA can enhance high morbidity and mortality diseases because of its multisystem involvement and its high prevalence.

Osteoporosis is defined as a skeletal disorder characterized by compromised bone strength that predisposes individuals to an increased risk of fracture (4). Its clinical spectrum ranges from asymptomatic bone loss to disabling fractures. In the United States, there are 1.5 million osteoporotic fractures per year, with an annual direct cost of nearly $\$ 18$ billion (5). Therefore, osteoporosis itself has a significant impact on patient quality of life and appears to be an escalating public health burden.

Several risk factors play a role in the development of osteoporosis including age, gender, race, hormone, diet and 
steroid use. Recent studies suggest that OSA is a contributing factor to osteoporosis as hypoxia reduces the growth of osteoblasts and stimulates osteoclasts resulting in the thinning of bone that eventually becomes osteoporosis (6). A recent study suggested that chronic intermittent hypoxia (IH) stimulated mesenchymal stem cell (MSC) mobilization, intensifying osteoblast formation in animal models and preserving bone homeostasis (7). Another study claimed that intermittent hypoxia exerted a protective role with regard to age-related decline in bone density, reducing the prevalence of osteopenia/osteoporosis in the elderly (8).

Despite evidence illustrating the pathogenesis of osteoporosis, to the best of our knowledge, there is still no conclusive study that has clearly shown whether OSA could be a risk or protective factor for osteoporosis. An understanding of a correlation between OSA and osteoporosis might help prevent osteoporosis, which is essential as it is often undertreated and under recognized because of its clinically silent character.

\section{Objectives}

We performed a systematic review and meta-analysis of observational studies to clarify the association between OSA and the prevalence or incidence of osteoporosis.

\section{Data Sources}

This systematic review and meta-analysis was conducted and reported according to the Meta-analysis Of Observational Studies in Epidemiology (MOOSE) statement (9) and was registered in PROSPERO (registration number: CRD42014014821).

\subsection{Search Methods for Identification of Studies}

A.S. and S.U. independently searched published studies indexed in MEDLINE and EMBASE from database inception to November 2015. References of selected retrieved articles were also examined. Search terms used included: osteoporosis, osteopenia, bone density, bone mass, bone loss, sleep apnea, obstructive sleep apnea, sleep-related breathing disorder. The full search terms used are detailed in the supplementary material. We hand-searched bibliographies of retrieved papers for additional references.

\section{Study Selection}

\subsection{Inclusion and Exclusion Criteria}

We included all published observational studies including prospective cohort, retrospective cohort, casecontrol, and cross-sectional studies evaluating incidence or prevalence of osteoporosis or bone mineral density in patient with sleep apnea or obstructive sleep apnea and compared with controls were included. We excluded reviews, case reports, letters, commentaries, and abstracts because they could not be evaluated for quality of study.

\subsection{Participants}

Studies that investigated participants 18 years of age or older who were assessed for sleep problems and had polysomnography measured and did not have osteoporosis at baseline were included.

\subsection{Obstructive sleep apnea definitions}

Obstructive sleep apnea was diagnosed by polysomnography or sleep study. The severity of OSA was characterized using the apnea-hypopnea index (AHI), which measures the number of apneas or hypopneas recorded during the study per hour of sleep. Based on the AHI, the severity of OSA was classified as follows: None/Minimal: AHI $<5$ per hour; Mild: AHI $\geq 5$, but $<$ 15 per hour; Moderate: AHI $\geq 15$, but $<30$ per hour; and Severe: AHI $\geq 30$ per hour.

\subsection{Outcome Measures}

The primary outcomes were incidence, prevalence, relative risk or odds ratio of having osteoporosis, which was defined as having a bone mineral density (BMD) with a Tscore of less than -2.5 SD as measured by dual-energy x-ray absorptiometry at spine and femoral neck. Differences in levels of BMD between patients with OSA and participants without OSA (controls) at lumbar spine and femur were the secondary outcome.

\section{Data Extraction}

\subsection{Data Collection and Analysis}

\subsubsection{Data Extraction and Management}

Two study investigators (A.S. and S.U.) independently reviewed the titles and abstracts of all identified citations. The inclusion criteria were independently applied to all identified studies. Differing decisions were resolved by consensus. Full-text versions of potentially relevant papers identified in the initial screening were retrieved. If multiple articles from the same study were found, only the article with the longest follow-up period was included. Data concerning study author's last name, year of publication, study design, study duration, source of population, number of participants, participant characteristics, and outcome measures were independently extracted. We planned to contact the authors of the primary reports to request any unpublished data. If the authors did not reply, we planned to use the available data for our analyses. 


\subsection{Assessment of Bias Risk}

The quality of observational studies (OBS) was evaluated by two investigators using the Newcastle-Ottawa quality assessment scale (10). The NOS is based on three major components: selection of the study groups ( 0 - 4 stars), comparability of cohorts and controls ( 0 - 2 stars), and ascertainment of outcome (0 - 3 stars). Discrepant opinions between authors were resolved by consensus. A total score of 3 or less was considered poor, 4 - 6 was considered moderate, and 7 - 9 was deemed high quality. We excluded poor quality study in the meta-analysis.

\subsection{Statistical Methods}

Data analysis was performed using Comprehensive Meta-Analysis 3.3 software from Biostat, Inc. We reported the pooled odds ratio of osteoporosis comparing between OSA and controls using a random effects model because of the high likelihood of between-study heterogeneity. We also reported the pooled mean difference (MD) of a BMD between OSA and control groups in each anatomical site. The heterogeneity of effect size estimates across these studies was quantified using the $\mathrm{I}^{2}$ statistic and Q statistic (11). For Q statistic, substantial heterogeneity was defined as P $<0.1$. The $\mathrm{I}^{2}$ statistic ranges in value from 0 to $100 \%\left(\mathrm{I}^{2}<\right.$ $25 \%$, low heterogeneity; $\mathrm{I}^{2}=25 \%-50 \%$, moderate heterogeneity; and $\mathrm{I}^{2}>50 \%$, substantial heterogeneity). We performed subgroup analysis by gender. We planned to perform meta-regression and publication bias if there were more than five included studies in the meta-analysis.

\section{Results}

\subsection{Description of Included Studies}

The initial search yielded 353 articles (Figure 1) of which 344 articles were excluded because they were not original observational studies (114 articles), participants did not have osteoporosis or BMD as outcomes (154 articles), or did not have OSA (76 articles). A total of 9 articles underwent full-length review. Data were extracted from 7 studies $(6,8$, 12-16) involving 113,558 participants. Three studies had cohort and cross-sectional designs, and one study had casecontrol design. The characteristics of the extracted studies included in this review are outlined in Table 1.

\subsection{Quality Assessment of Included Studies}

The quality of included studies were evaluated by NOS (Table 1). Total score ranged from 4-9. Uzkeser et al. (13) had lowest quality (total score $=4$ ). Chen et al. (6) had the highest quality (total score $=9$ ). No studies were excluded for having poor quality (total score $<4$ ).

\subsection{Quantitative Results (Meta-Analysis)}

\subsubsection{Osteoporosis}

Three studies $(6,8,12)$ were included in the metaanalysis of incidence or prevalence of osteoporosis (Figure 2). The analysis revealed that odds of osteoporosis were higher in participants with OSA compared with controls among cohort studies $(6,12)$ with pooled OR of 1.92 (95\% confidence interval [CI]:1.24 - 2.97). The statistical betweenstudy heterogeneity was moderate with an $\mathrm{I}^{2}$ of $66 \%, \mathrm{P}=$ 0.09. Among cross-sectional studies (8), odds of osteoporosis were higher in participants with controls with pooled OR of 0.60 (95\% CI: 0.42 - 0.87). The statistical betweenstudy heterogeneity was low with an $\mathrm{I}^{2}$ of $0 \%, \mathrm{P}=0.93$.

In subgroup analysis by gender (Figure 3), both male $(\mathrm{OR}=2.03,95 \% \mathrm{CI}: 1.24-3.35)$ and female $(\mathrm{OR}=2.56,95 \%$ CI: 1.96 - 3.34) also had higher odds of osteoporosis in OSA compared with control groups among cohort studies (Pvalue for interaction $=0.82$ ). Among cross-sectional studies, there was no difference in odds of osteoporosis in both male (OR $=0.63,95 \% \mathrm{CI}: 0.33-1.19)$ and female $(\mathrm{OR}=0.90$, 95\% CI: $0.58-1.40)($ P-value for interaction $=0.43$ ).

\subsubsection{Bone Mineral Density}

Five cross-sectional studies $(8,13-16)$ were included in the meta-analysis of BMD at the lumbar spine (Figure 4). There was a significant lower BMD in the OSA group with a pooled mean difference (MD) of 0.06 (95\% CI: 0.005 - 0.111) compared with control. The statistical between-study heterogeneity was moderate with an $\mathrm{I}^{2}$ of $39 \%, \mathrm{P}=0.16$. Four studies $(8,13,14,16)$ were included in the meta-analysis of BMD at the femur (Figure 5). There was no significant difference in BMD with a pooled MD of 0.04 (95\% CI:-0.004 to 0.09). The statistical between-study heterogeneity was low with an $\mathrm{I}^{2}$ of $0 \%, \mathrm{P}=0.52$.

\subsection{Sensitivity Analysis and Publication Bias}

Sensitivity analysis, meta-regression, and publication bias were not performed because there were too few included studies in the analysis.

\section{Discussion}

This is the first systematic review and meta-analysis of published observational studies to evaluate the association between obstructive sleep apnea and osteoporosis. The result suggests that odds of osteoporosis is higher in patients with OSA in both genders. However, in crosssectional studies, odds of osteoporosis is lower in patients with OSA compared with controls. There is little difference in bone mineral density at lumbar spine, which is higher in the control group. 


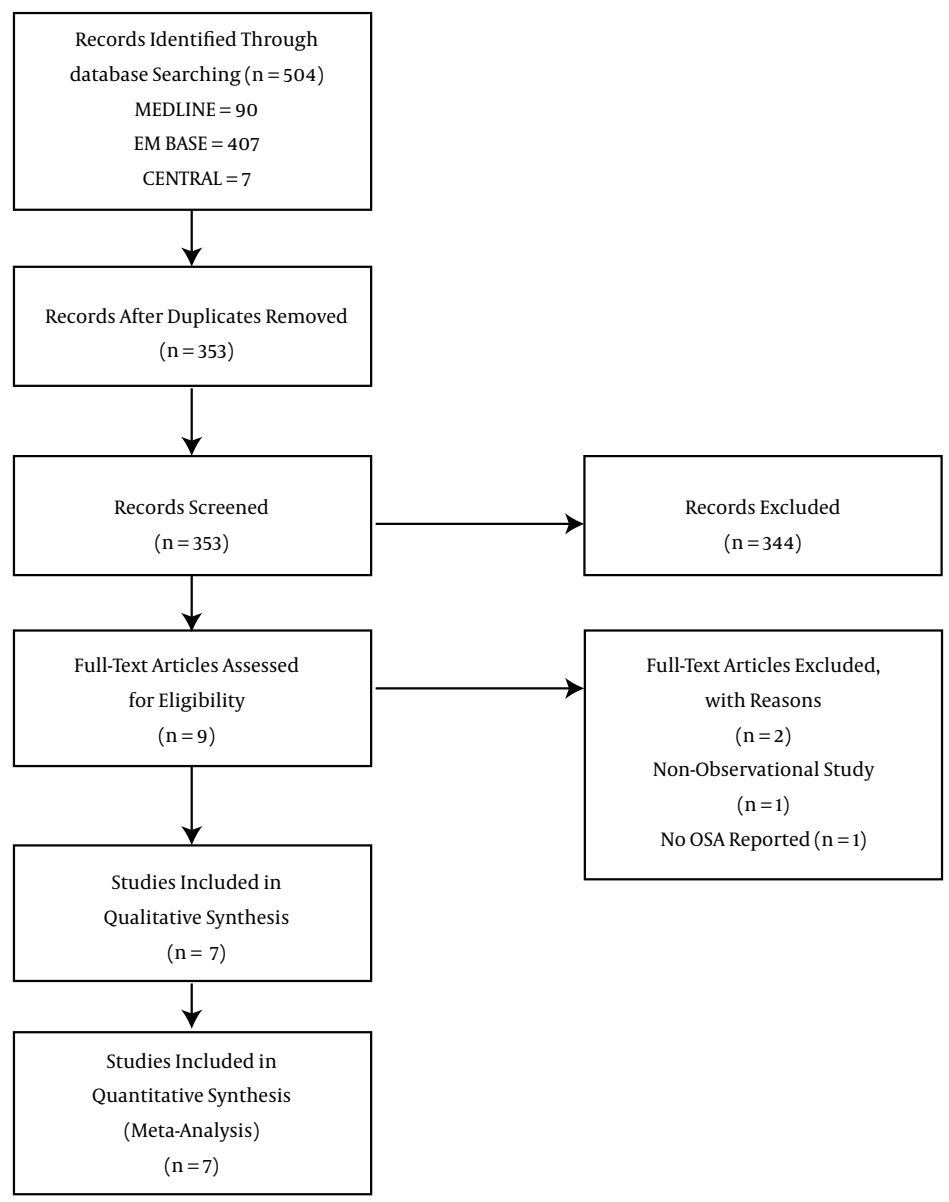

Figure 1. Flow Chart of Study Selected for Inclusion in the Systematic Review

\begin{tabular}{|c|c|c|c|c|c|c|c|c|}
\hline \multirow[t]{2}{*}{ Study Design } & \multirow[t]{2}{*}{ Study Name } & \multirow[t]{2}{*}{ Subgroup } & \multicolumn{4}{|c|}{ Statistics for Each Study } & \multicolumn{2}{|c|}{ Sample Size } \\
\hline & & & $\begin{array}{l}\text { Odds } \\
\text { Ratio }\end{array}$ & $\begin{array}{r}\text { Lower } \\
\text { Limit }\end{array}$ & $\begin{array}{l}\text { Upper } \\
\text { Limit }\end{array}$ & Z-Value & OSA & Normal \\
\hline \multirow{2}{*}{ Cohort } & Chen & & 2.52 & 1.58 & 4.02 & 3.90 & 1377 & 20655 \\
\hline & Yen & & 1.60 & 1.27 & 2.02 & 3.98 & 846 & 89380 \\
\hline \multicolumn{2}{|c|}{$\operatorname{Total}\left(1^{2}=66 \%, \mathrm{p}=0.09\right)$} & & 1.92 & 1.24 & 2.97 & 2.93 & & \\
\hline \multirow{2}{*}{ Cross-Sectional } & Sforza & Femur & 0.59 & 0.29 & 1.19 & -1.49 & 459 & 373 \\
\hline & Sforza & Lumbar & 0.61 & 0.40 & 0.94 & -2.27 & 459 & 373 \\
\hline \multicolumn{2}{|c|}{$\operatorname{Total}\left(\mathrm{l}^{2}=0 \%, \mathrm{p}=0.93\right)$} & & 0.60 & 0.42 & 0.87 & -2.71 & & \\
\hline
\end{tabular}

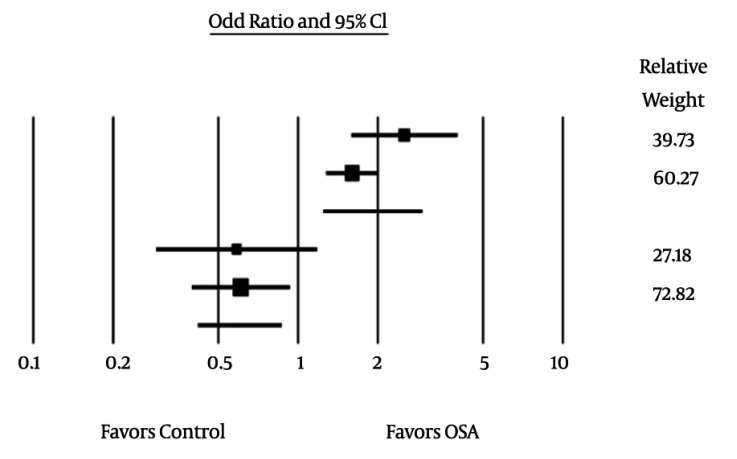

Figure 2. Forest Plot of Participants with Osteoporosis in OSA Compared with Controls

Osteoporosis is a multifactorial chronic systemic disease characterized by a reduction in bone mass, disruption of bone microarchitecture, and skeletal fragility (17, 18). Chronic intermittent hypoxia mimicking OSA has been related to proinflammatory cytokine production in animal models, but did not significantly modify BMD in a mouse study (7). Many diseases and medical conditions, especially the presence of heart disease, depression, arthritis 
Table 1. Characteristics of the Included Studies ${ }^{\mathrm{a}}$

\begin{tabular}{|c|c|c|c|c|c|c|c|}
\hline Study & Yen 2014 & Chen 2014 & Sforza 2013 & Uzkeser 2013 & Yuceege 2015 & Wang 2015 & Terzi 2015 \\
\hline Design & $\begin{array}{l}\text { Retrospective } \\
\text { Cohort }\end{array}$ & $\begin{array}{l}\text { Retrospective } \\
\text { Cohort }\end{array}$ & Cross-sectional & Cross-sectional & Cross-sectional & Cross-sectional & Cross-sectional \\
\hline Country & Taiwan & Taiwan & France & Turkey & Turkey & Taiwan & Turkey \\
\hline Data source & $\begin{array}{l}\text { Population- } \\
\text { based cohort } \\
\text { from the } \\
\text { National Health } \\
\text { Insurance } \\
\text { Research } \\
\text { Database } \\
\text { (NHIRD) }\end{array}$ & $\begin{array}{l}\text { Longitudinal } \\
\text { Health } \\
\text { Insurance } \\
\text { Database }\end{array}$ & $\begin{array}{l}\text { Population- } \\
\text { based cohort of } \\
\text { volunteers age } \\
65 \text { years in } \\
\text { France }\end{array}$ & $\begin{array}{l}\text { Sleep disorders } \\
\text { laboratory in } \\
\text { Ataturk } \\
\text { University }\end{array}$ & $\begin{array}{l}\text { Patients referred } \\
\text { to Respiratory } \\
\text { and Sleep Clinic }\end{array}$ & $\begin{array}{l}\text { Medical records } \\
\text { at a tertiary } \\
\text { hospital in } \\
\text { Taiwan }\end{array}$ & $\begin{array}{l}\text { Sleep } \\
\text { laboratories }\end{array}$ \\
\hline Study duration & $1998-2001$ & $2000-2008$ & Seven years & $\mathrm{N} / \mathrm{A}$ & $\begin{array}{l}\text { January } 2012 \text { and } \\
\text { March } 2013\end{array}$ & $\begin{array}{l}\text { January } 2008 \text { to } \\
\text { January } 2013\end{array}$ & $2012-2013$ \\
\hline $\begin{array}{l}\text { Participants' } \\
\text { characteristics }\end{array}$ & $\begin{array}{l}\text { Apnea sleep } \\
\text { disorders } \\
\text { diagnosed by } \\
\text { PSG }\end{array}$ & $\begin{array}{l}\text { OSA diagnosed } \\
\text { by PSG or } \\
\text { hospitalization } \\
\text { with OSA }\end{array}$ & $\begin{array}{l}\text { Prior treatment } \\
\text { or diagnosis of } \\
\text { OSA }\end{array}$ & $\begin{array}{l}\text { Men who } \\
\text { underwent PSG }\end{array}$ & $\begin{array}{l}\text { Younger than } 45 \\
\text { years old, } \\
\text { snoring, } \\
\text { witnessed apnea } \\
\text { and/or excessive } \\
\text { daytime } \\
\text { sleepiness, with } \\
\text { no known } \\
\text { comorbidities }\end{array}$ & $\begin{array}{l}\text { COPD patients } \\
\text { with available } \\
\text { PSG with no } \\
\text { malignancy }\end{array}$ & $\begin{array}{l}\text { Males who had } \\
\text { PSG test }\end{array}$ \\
\hline OSA diagnosis & $\begin{array}{l}\text { ICD-9-CM code in } \\
\text { medical records }\end{array}$ & $\begin{array}{l}\text { ICD-9-CM code in } \\
\text { medical records }\end{array}$ & $\begin{array}{l}\text { AHI 15-30/hour: } \\
\text { mild OSA, AHI } \geq \\
\text { 30/hour: severe } \\
\text { OSA }\end{array}$ & $\begin{array}{l}\text { apnea/hypopnea } \\
\text { in the presence } \\
\text { of thoraco- } \\
\text { abdominal } \\
\text { effort }\end{array}$ & $\mathrm{AHI} \geq 30$ & $\begin{array}{l}\mathrm{AHI}>15 / \text { hour, } \\
\$ 50 \% \text { were } \\
\text { obstructive }\end{array}$ & $\begin{array}{l}\text { AHI 5-15/hour: } \\
\text { mild OSA, 15 - } \\
\text { 30/hour: } \\
\text { moderate OSA, } \\
\geq 30 / \text { hour: } \\
\text { severe OSA }\end{array}$ \\
\hline $\begin{array}{l}\text { Number of } \\
\text { participants }\end{array}$ & 90,226 & 22,032 & 832 & 21 & 85 & 312 & 50 \\
\hline Age & $48.9(14.5)$ & $>40$ years & $68.6(0.03)$ & $54(37-69)$ & $35.5 \pm 5.7$ & $71.5 \pm 5.78 .5$ & $52.37 \pm 8.58$ \\
\hline Comorbidity & $\begin{array}{l}\text { DM, HTN, DLP, } \\
\text { CKD, COPD }\end{array}$ & $\begin{array}{l}\text { DM, HTN, DLP, } \\
\text { CKD, CAD, stroke }\end{array}$ & $\begin{array}{l}\text { DM, DLP, } \\
\text { smoking }\end{array}$ & & & COPD & $\begin{array}{l}\text { Smoking, } \\
\text { hypertension }\end{array}$ \\
\hline Lumbar BMD & & & $0.97 \pm 1.6$ & $0.9(0.6-1.1)$ & $-0.79 \pm 1.2$ & & $1.08 \pm 0.15$ \\
\hline $\begin{array}{l}\text { Femur neck } \\
\text { BMD }\end{array}$ & & & $0.86 \pm 1.46$ & $0.8(0.7-1.2)$ & $-0.61 \pm 0.9$ & & $1.04 \pm 0.15$ \\
\hline Lumbar T score & & & & $-1.1(-3.7-0.2)$ & $0.98 \pm 0.1$ & & \\
\hline \multirow[t]{2}{*}{ Femur T score } & & & & $-0.4(-2.1-1.7)$ & $0.98 \pm 0.1$ & & \\
\hline & Selection $=4$ & Selection $=4$ & Selection $=3$ & Selection $=2$ & Selection $=3$ & Selection $=3$ & Selection $=2$ \\
\hline \multirow[t]{2}{*}{ NOS } & $\begin{array}{l}\text { Comparability }= \\
2\end{array}$ & $\begin{array}{l}\text { Comparability }= \\
2\end{array}$ & $\begin{array}{l}\text { Comparability }= \\
0\end{array}$ & $\begin{array}{l}\text { Comparability = } \\
1\end{array}$ & $\begin{array}{l}\text { Comparability = } \\
1\end{array}$ & $\begin{array}{l}\text { Comparability }= \\
2\end{array}$ & $\begin{array}{l}\text { Comparability= } \\
1\end{array}$ \\
\hline & Exposure $=2$ & Exposure $=3$ & Exposure $=2$ & Exposure $=1$ & Exposure $=2$ & Exposure $=2$ & Exposure $=2$ \\
\hline
\end{tabular}

Abbreviations: BMI, Body mass index; CAD, coronary artery disease; CKD, chronic kidney disease; COPD, chronic obstructive pulmonary disease; DLP, dyslipidemia; DM diabetes mellitus; HTN, hypertension; OSA, Obstructive sleep apnea; PSG, polysomnography.

${ }^{a}$ Data are presented as mean \pm S.D., or median (minimum - maximum).

and obesity, are associated with an increased prevalence of sleep disturbances including symptoms of insomnia, daytime sleepiness, and restless leg syndrome (19). A previous study also demonstrated that severe OSA was associated with increased bone resorption by measuring metabolic markers independent of BMI, which was reversed by continuous positive airway pressure (CPAP) therapy (20). However, our analysis found a significant association of osteo- porosis and OSA only in cohort studies, but we did not find an association in cross-sectional studies. There is a small difference in BMD only at lumbar spine between patients and controls. This may be in part due to findings that higher body weight is beneficial to bone health because of the well-established positive effect of mechanical loading conferred by body weight on bone formation $(21,22)$, despite being a risk factor for many other chronic disorders. 


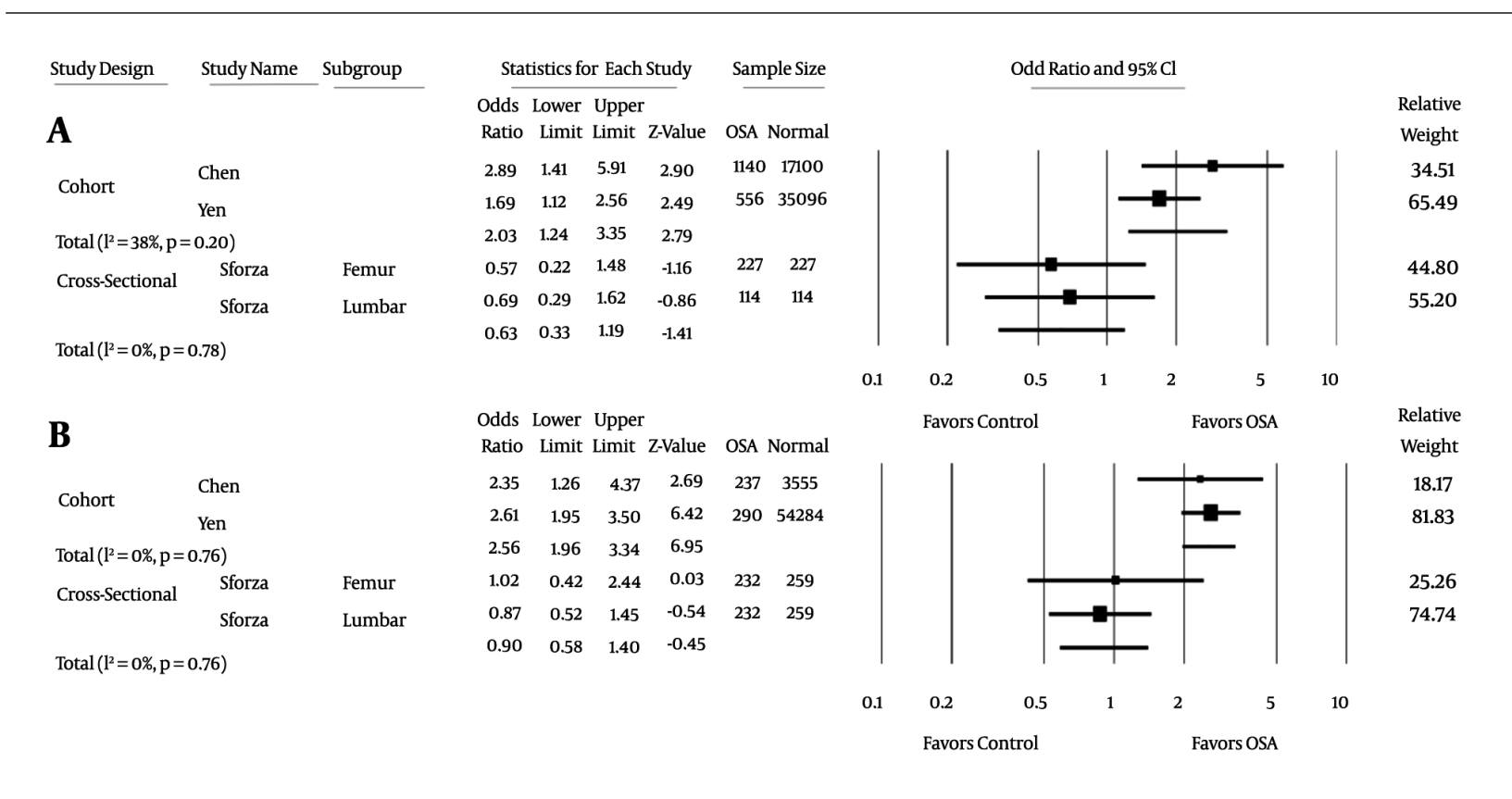

Figure 3. Forest plot of Participants with Osteoporosis in OSA Compared with Controls by Subgroup of Gender ( $A=$ Male, $B=$ Female)

\begin{tabular}{|c|c|c|c|c|c|}
\hline \multirow[t]{3}{*}{ Study Name } & \multirow{3}{*}{$\begin{array}{l}\text { Difference } \\
\text { in Means }\end{array}$} & \multicolumn{3}{|c|}{ Statistics for Each Study } & \multirow[b]{3}{*}{ Z-Value } \\
\hline & & Standard & Lower & Upper & \\
\hline & & Error & Limit & Limit & \\
\hline Sforza & 0.040 & 0.095 & -0.146 & 0.226 & 0.421 \\
\hline Terzi & -0.080 & 0.041 & -0.161 & 0.001 & -1.946 \\
\hline Uzkeser & -0.025 & 0.033 & -0.089 & 0.039 & -0.762 \\
\hline Wang & -0.720 & 0.351 & -1.407 & -0.033 & -2.054 \\
\hline Yuceege & -0.080 & 0.027 & -0.133 & -0.027 & 2.941 \\
\hline $\operatorname{Total}\left(1^{2}=39 \%, p=0.16\right)$ & -0.058 & 0.027 & -0.111 & -0.005 & -2.133 \\
\hline
\end{tabular}

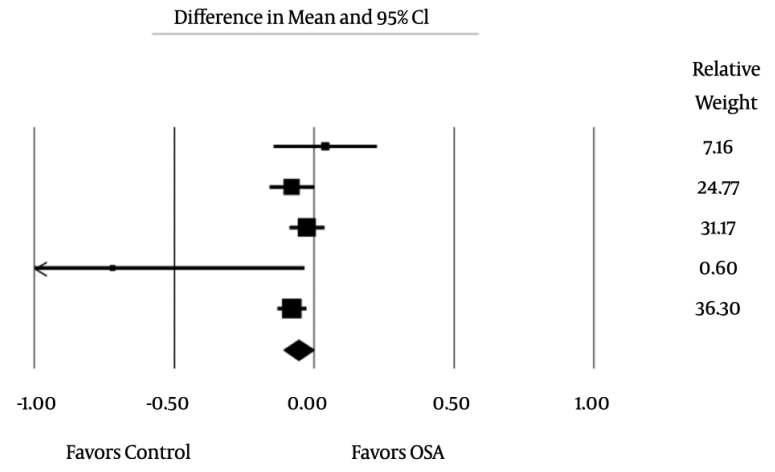

Figure 4. Forest Plot of Bone Mineral Density at the Lumbar Spine in OSA Compared with Controls

Mariani et al. (23) found no correlation between AHI and BMD in obese participants with OSA, which contributed to the positive association of lean mass that was higher in moderate and severe OSA groups and BMD. There is still controversial question of whether OSA is associated with osteoporosis even with the results of this meta-analysis.

\subsection{Limitations}

There are several limitations in our review; therefore, our results should be interpreted with caution. First, the major limitation was the small number of studies that met our inclusion criteria; only three studies were included in the meta-analysis of osteoporosis and four to five studies in the analysis of BMD. Second, the results analyzed were from observational studies, which might be affected by factors such as selection bias, where participants do not represent the general population or a lack of description of non-OSA participants. Studies may have potential confounders such as age, gender, BMI, medication use, and comorbidities, all of which might affect the risk of osteoporosis. Third, subgroup analysis, meta-regression, and funnel plot to detect publication bias were not performed because there were too few studies included in the analysis. 


\begin{tabular}{lccccc} 
Study Name & & \multicolumn{3}{c}{ Statistics for Each Study } \\
\cline { 3 - 6 } & $\begin{array}{l}\text { Difference } \\
\text { in Means }\end{array}$ & $\begin{array}{c}\text { Standard } \\
\text { Error }\end{array}$ & $\begin{array}{c}\text { Lower } \\
\text { Limit }\end{array}$ & $\begin{array}{c}\text { Upper } \\
\text { Limit }\end{array}$ & Z-Value \\
Sforza & 0.040 & 0.100 & -0.156 & 0.236 & 0.400 \\
Terzi & -0.110 & 0.203 & -0.507 & 0.287 & -0.543 \\
Uzkeser & -0.025 & 0.060 & -0.142 & 0.092 & -0.417 \\
Yuceege & 0.060 & 0.027 & 0.006 & 0.114 & 2.196 \\
Total $\left(\mathrm{l}^{2}=0 \%, \mathrm{p}=0.52\right)$ & 0.043 & 0.024 & -0.004 & 0.090 & 1790
\end{tabular}

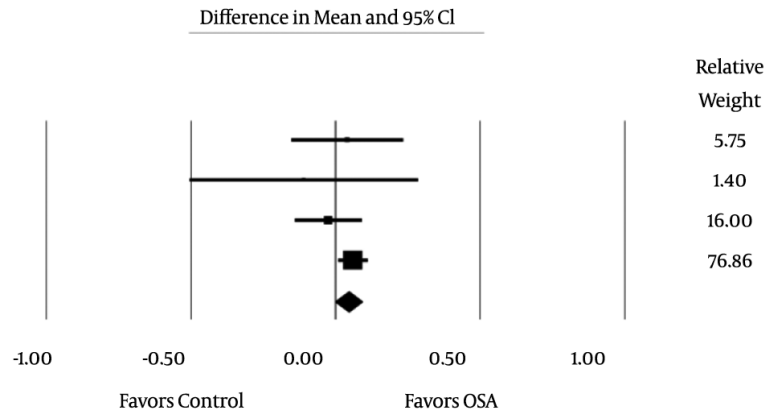

Figure 5. Forest Plot of Bone Mineral Density at the Femur in OSA Compared with Controls

\subsection{Conclusions}

We found a different association between OSA and osteoporosis which depends on study design. It should be noted that the results of our meta-analysis of observational studies should be interpreted with caution as the studies analyzed might contain different population characteristics. Further controlled studies involving a greater number of patients with adjusted effects for age, sex, or BMI are needed to investigate the relationship between osteoporosis and OSA.

\section{Supplementary Material}

Supplementary material(s) is available here.

\section{Footnotes}

Authors' Contribution: Sikarin Upala, provided the study concept and design, interpreted data, and reviewed/edited the manuscript; Anawin Sanguankeo, analyzed and interpreted data, performed statistical analysis, wrote the manuscript, and reviewed/edited the manuscript; Soontharee Congrete, reviewed/edited the manuscript.

Conflict of Interest: We do not have any financial or nonfinancial potential conflicts of interest.

\section{References}

1. Young T, Palta M, Dempsey J, Skatrud J, Weber S, Badr S. The occurrence of sleep-disordered breathing among middle-aged adults. $N$ Engl J Med. 1993;328(17):1230-5. doi: 10.1056/NEJM199304293281704. [PubMed: 8464434].

2. Labarca G, Cruz NR, Descalzi F. [Multisystemic involvement in obstructive sleep apnea]. Rev Med Chil. 2014;142(6):748-57. doi: 10.4067/S0034-98872014000600009. [PubMed: 25327320].

3. Lattimore JD, Celermajer DS, Wilcox I. Obstructive sleep apnea and cardiovascular disease. JAm Coll Cardiol. 2003;41(9):1429-37. [PubMed: 12742277].
4. NIH Consensus Development Panel on Osteoporosis Prevention, Diagnosis, and Therapy, March 7-29, 2000: highlights of the conference. South Med J. 2001;94(6):569-73. [PubMed: 11440324].

5. Gabriel SE, Tosteson AN, Leibson CL, Crowson CS, Pond GR, Hammond CS, et al. Direct medical costs attributable to osteoporotic fractures. Osteoporos Int. 2002;13(4):323-30. [PubMed:12035765].

6. Chen YL, Weng SF, Shen YC, Chou CW, Yang CY, Wang JJ, et al. Obstructive sleep apnea and risk of osteoporosis: a population-based cohort study in Taiwan. J Clin Endocrinol Metab. 2014;99(7):2441-7. doi: 10.1210/jc.2014-1718. [PubMed: 24735427].

7. Torres M, Montserrat JM, Pavia J, Dalmases M, Ros D, Fernandez Y, et al. Chronic intermittent hypoxia preserves bone density in a mouse model of sleep apnea. Respir Physiol Neurobiol. 2013;189(3):646-8. doi: 10.1016/j.resp.2013.08.016. [PubMed: 23994179].

8. Sforza E, Thomas T, Barthelemy JC, Collet P, Roche F. Obstructive sleep apnea is associated with preserved bone mineral density in healthy elderly subjects. Sleep. 2013;36(10):1509-15. doi: 10.5665/sleep.3046. [PubMed: 24082310].

9. Liberati A, Altman DG, Tetzlaff J, Mulrow C, Gotzsche PC, Ioannidis JP, et al. The PRISMA statement for reporting systematic reviews and meta-analyses of studies that evaluate health care interventions: explanation and elaboration. Ann Intern Med. 2009;151(4):6594. [PubMed: 19622512].

10. Stang A. Critical evaluation of the Newcastle-Ottawa scale for the assessment of the quality of nonrandomized studies in meta-analyses. Eur J Epidemiol. 2010;25(9):603-5. doi: 10.1007/s10654-010-9491-z. [PubMed: 20652370].

11. Higgins JP, Thompson SG, Deeks JJ, Altman DG. Measuring inconsistency in meta-analyses. BMJ. 2003;327(7414):557-60. doi: 10.1136/bmj.327.7414.557. [PubMed: 12958120].

12. Yen CM, Kuo CL, Lin MC, Lee CF, Lin KY, Lin CL, et al. Sleep disorders increase the risk of osteoporosis: a nationwide population-based cohort study. Sleep Med. 2014;15(11):1339-44. doi: 10.1016/j.sleep.2014.07.005. [PubMed: 25224072].

13. Uzkeser H, Yildirim K, Aktan B, Karatay S, Kaynar H, Araz O, et al. Bone mineral density in patients with obstructive sleep apnea syndrome. Sleep Breath. 2013;17(1):339-42. doi: 10.1007/s11325-012-0698-y. [PubMed: 22467193].

14. Yuceege M, Dulgeroglu DE, Firat H, Yalcındag A. Can sleep apnea be a secondary cause of osteoporosis in young people?. Sleep Biol Rhythms. 2015;13(2):189-94.

15. Wang TY, Lo YL, Chou PC, Chung FT, Lin SM, Lin TY, et al. Associated bone mineral density and obstructive sleep apnea in chronic obstructive pulmonary disease. Int J Chron Obstruct Pulmon Dis. 2015;10:231-7. doi: 10.2147/COPD.S72099. [PubMed: 25673983]. 
16. Terzi R, Yilmaz Z. Bone mineral density and changes in bone metabolism in patients with obstructive sleep apnea syndrome. $J$ Bone Miner Metab. 2015 doi: 10.1007/s00774-015-0691-1. [PubMed: 26204846].

17. Stobaugh DJ, Deepak P, Ehrenpreis ED. Increased risk of osteoporosisrelated fractures in patients with irritable bowel syndrome. Osteoporos Int. 2013;24(4):1169-75. doi: 10.1007/s00198-012-2141-4. [PubMed: 22993020].

18. Guiglia R, Di Fede O, Lo Russo L, Sprini D, Rini GB, Campisi G. Osteoporosis, jawbones and periodontal disease. Med Oral Patol Oral Cir Bucal. 2013;18(1):93-9. [PubMed: 23229255].

19. Foley D, Ancoli-Israel S, Britz P, Walsh J. Sleep disturbances and chronic disease in older adults: results of the 2003 National Sleep Foundation Sleep in America Survey.JPsychosom Res. 2004;56(5):497502. doi: 10.1016/j.jpsychores.2004.02.010. [PubMed: 15172205].
20. Tomiyama H, Okazaki R, Inoue D, Ochiai H, Shiina K, Takata Y, et al Link between obstructive sleep apnea and increased bone resorption in men. Osteoporos Int. 2008;19(8):1185-92. doi: 10.1007/s00198-007 0556-0. [PubMed: 18224268].

21. Reid IR. Relationships among body mass, its components, and bone. Bone. 2002;31(5):547-55. [PubMed:12477567].

22. Felson DT, Zhang Y, Hannan MT, Anderson JJ. Effects of weight and body mass index on bone mineral density in men and women: the Framingham study. J Bone Miner Res. 1993;8(5):567-73. doi: 10.1002/jbmr.5650080507. [PubMed: 8511983].

23. Mariani S, Fiore D, Varone L, Basciani S, Persichetti A, Watanabe M, et al Obstructive sleep apnea and bone mineral density in obese patients. Diabetes Metab Syndr Obes. 2012;5:395-401. doi: 10.2147/DMSO.S37761. [PubMed: 23152692]. 